\title{
From Reality to Subject: A Sympathetic, Yet Critical Reading of Eliade
}

\author{
TEUVO LAITILA \\ University of Joensuu
}

\begin{abstract}
Mircea Eliade is, or at least has been, the most heavily criticised scholar of religions. A number of critics have been discontented with his 'uncritical' way of using data to illustrate or assert his insights. It has been said that Eliade's presuppositions about the nature of reality and religion are not scientific but metaphysical or theological. Eliade's sympathisers, on the other hand, have tried to show that he does after all have a method, and that a careful reading demonstrates that either his presuppositions are no more unscientific than those of anyone else or they can be rethought in a scientifically acceptable way. My startingpoint is both sympathetic and critical. My question is, what is Eliade actually attempting to understand when he states that he wants to understand religion at its own level? He himself states that he wants to unmask the 'revelations' of the sacred, or - as he also says - the transcendent, and their significance for modern man, who has lost his comprehension of both the sacred and its meaning. This he can do, he argues, by recapturing the way in which 'primitive' and 'archaic' cultures and ancient and modern traditions outside mainstream religions have used symbols to establish a patterned, harmonised view of the world, or - as Eliade prefers to say - reality. Both Eliade's critics and his sympathisers presumably agree that Eliade's presuppositions include statements about the 'essence' of religion, about the nature of reality, and about the ways religion operates, or should operate, in human life, or mode-of-being-in-the-world; they also agree that one of Eliade's main concern in religious studies is with symbols. In my article, I deal with these four points (essence, reality, mode-of-being and symbols), proposing a reading of Eliade which emphasises the scholar's encounter with the subject and not the 'essence' of the matter under study. In my conclusion I suggest that studying the ways in which humans use symbols, which they connect with the 'real' to construct a 'mode-of-being' - or, as William Paden put it, a 'world' - is one way of going 'beyond' Eliade.
\end{abstract}

Keywords: Mircea Eliade, phenomenology of religion, methodology, religious studies

Mircea Eliade is, or at least has been, the most heavily criticised scholar of religions. A number of critics have been discontented with his 'uncritical' 
way of using data to illustrate or assert his insights. Many have expressed serious doubts about his method - or, rather, as they say, lack of it - and above all about his epistemology. It has been said that Eliade's presuppositions about the nature of reality and religion are not scientific but metaphysical or Gnostic. In other words, they are beyond everything that is scientifically acceptable. (See for example Dudley 1977; McCutcheon 2001; Saliba 1976.)

Eliade's sympathisers, on the other hand, have tried to show that he does after all have a method, and that a careful reading demonstrates that either his presuppositions are no more unscientific than those of anyone else or they can be rethought in a scientifically acceptable way. (See Laitila 2000; Marino 1981; Rennie 1996; Studstill 2000.)

My starting-point is simultaneously sympathetic and critical. I try to make sense of certain basic presuppositions and concepts in Eliade's thinking. But I also attempt a critical rethinking of them, in order to go, as Ninian Smart (1978) once put it, 'beyond Eliade'. 'Beyond', however, does not mean 'disregarding' his approach, but rather building on it.

My question is, what is Eliade actually attempting to understand when he states that he wants to understand religion at its own level, that of existence, not of politics, economics, etc.? He himself states that he wants to unmask the 'revelations' of the sacred, or - as he also says - the transcendent, and their significance for modern man, who has lost his comprehension of both the sacred and its meaning. (See for example Eliade 1961a; 1962, 11; 1977, 83.) This he can do, he argues, by recapturing the way in which 'primitive' and 'archaic' cultures, as well as ancient and modern traditions outside mainstream religions, use symbols to establish a patterned, harmonised view of 'reality' beyond space and time. (For example Eliade 1961b, 24-25; 1965, 174, 202-203; 1971, 83-84.) Nevertheless, he also emphasises that religious phenomena, such as myths, should be studied 'as what they are - cultural phenomena' (Eliade 1964, 4).

Both Eliade's critics and his sympathisers presumably agree that Eliade's presuppositions include statements about the 'essence' of religion, about the nature of reality, and about the ways religion operates, or should operate, in human life, or mode-of-being-in-the-world; they also agree that one of Eliade's main concern in religious studies is with symbols. In what follows, I will deal with these four points - essence, reality, mode-of-being, and symbols - in that order.

My selection of these four concepts implies a particular understanding of religion. I suppose (in the manner of Eliade, I assume) that for homo religiosus religion has an essence, or structure, which from his or her view 
is at a given moment 'eternal', although it may manifest itself in different forms. Part of our task as scholars of religion is to figure out the way in which homo religiosus understands this structure and explicates it, in words, deeds and symbols, to create a 'coherent' world - or, as Eliade puts it, 'mode-of-being'.

As I see the matter, Eliade's approach to religion involves not only a method but also a personal commitment to the 'reality' of 'homo religiosus' and a particular understanding of it. Eliade seems to assume that homo religiosus is not merely a religious person, but is 'liberated' or 'enlightened' in the way of a yogi or a Buddha (see Eliade 1965, 94-95). It is this sort of homo religiosus whose understanding of religion Eliade wants to illuminate. He does not question the ontology implied or explicated by a homo religiosus. Eliade argues that in order to understand him or her we merely have to describe his or her ways of perceiving the world, his or her actions and evaluations of things, acts and ideas. I think that Eliade is right in insisting that if we want to understand religion from a religious person's point of view we have to acknowledge his or her thinking and emotions as 'real'. But we cannot stop here.

\section{Essence or Structure of Religion}

Following Rudolf Otto, Eliade defines religion as the sacred, as opposed to the profane (see Eliade 1971). The sacred in turn is something powerful, something 'utterly other' than human beings (Eliade 1965, 122). It is a synonym for 'real', something that is the Urgrund of everything and cannot be fully explained. At the same time, it is something that gives meaning to that foundation of existence. (Cf. 1965, 173, 206-207.) It is hard not to conclude that for Eliade religion has an essence. At least most, if not all, of Eliade's critics drew this conclusion; they also jumped to another, namely that this 'essence' is somehow comparable to, if not synonymous with, what Christians (or Muslims or Jews) would call God.

In my opinion, this is a hasty conclusion. It is true that in many places Eliade uses Christian or quasi-Christian terminology, speaking of 'revelation', 'fall', 'hope', and so on. It is also true that he essentialises the source of religion. But critics have seldom, to my knowledge, asked why he actually used this kind of terminology and what, in fact, he was 'essentialising'.

My guess is, that the works which have been most heavily criticised, such as The Myth of the Eternal Return, The Sacred and the Profane, and Patterns in Comparative Religion were written for a large audience, not for specialists. In the 1940s and 1950s when those works first appeared, their audience was 
largely secularised, but was still familiar with Christian terminology. It was for this reason, I assume, that Eliade chose to resort to it. In other words, his choice was not an expression or a statement of his own convictions about the 'essence' of religion, but a means of addressing his audience in a way that was familiar to it. He himself was always vague about what, ultimately, was the 'essence' of the sacred. The nearest equivalent to a specification of the sacred, or real, seems to me to be Eliade's habit of using the term 'religion' to refer to the ways and means by which human beings have tried to overcome the limits of space and time and to establish contact with something that could give a timeless meaning to their existence (Eliade 1964; 1965; 1971).

I also suppose that, in the manner of a mystic, Eliade wants to emphasise that religiosity is not fully within human consciousness and under conscious control. It is partly 'given'; it contains a dimension that 'pre-exists' in the human mind and conditions. Unlike Freud, Durkheim, Marx and others who consider religion to be fully explicable in terms of human agency, Eliade strongly stresses that for homo religiosus religiosity is a mixture of his or her actions and something outside human feasibility. In Myth and Reality, for example, he writes that ' $[\mathrm{t}]$ he real sacrilege is to forget the divine act [of creation]' (Eliade 1964, 107, emphasis in original). That is, for homo religiosus there is something in religion and reality that cannot be explained by human activities. In Eliade's thinking this 'something' is related to human existence. In The Two and the One, Eliade argues that '[e]very time man becomes aware of his true, existential situation, that is to say of his specific manner of existence in the Cosmos, and accepts this way of existence, he expresses these decisive experiences by images and myths which will afterwards enjoy a privileged position in the spiritual tradition of humanity' $(1965,174)$.

Eliade thus insists that religion, or the sacred, contains an 'essence' or structure that does not change. Why does he argue thus? Ninian Smart (1978, 181-182) proposed that the reason was Eliade's understanding of Romanian history. Eliade was desperately seeking some rallying point in Romanian history which might justify speaking of a constant element in Romanian identity. What Eliade did with religion, Smart claimed, was similar; only a constant element beyond time and place could justify one in speaking about religion. More recently, Steven Wasserstorm (1999) has suggested that, in the manner of the Gnostics and Jung, Eliade understood religion as a sort of eternal truth within humans themselves. I would say that Eliade was convinced that religion has an unchanging, ontological structure, which is inseparable from reality; but he also argued that this reality is perceived, 
and lived through, only in temporal and spatial changes (see Eliade 1964, 108-113). I return to this point later.

In a common hermeneutical way, Eliade suggests that when studying the other's way of seeing reality (or living out their religion), we have to bracket our subjective comprehension of it. We are not allowed to reduce another person's religion (or his or her notion of reality) to psychological, sociological, economic or other factors, if the other insists that there is something more to it than we can see. According to Eliade, in studying religion we have to 'essentialise' it in the manner in which the other perceives it. On the other hand, I would say, we are not allowed to privilege the other's position (that of archaic or primitive man) as a norm - and that is what Eliade seems to do. He argues (1961b, 35), that archaic religion is somehow more authentic, more complete or truer to some unspecific 'genuine' human nature than the modern, unauthentic one. The reason for this in Eliade's opinion is that a modern person is 'bound' by history - or, more specifically, by time $(1965,94-95)$ - and is for this reason alienated from his or her 'true' nature. My conclusion is that Eliade essentialises religion in order to 'save' the perspective of homo religiosus, the 'eternally same' structure and timelessness of religion.

Such an argument seems to form a deadlock, unless we rethink it, for example by supposing that what Eliade is speaking about is not the 'essence' of religion as such, but the way in which homo religiosus, in Eliade's opinion, structures religion. In other words, we are not conceptualising the 'essence' of religion, but the way homo religiosus perceives it, or - as some might put it - constructs, at a particular moment. In this sense we can speak of essentialising religion or the sacred. However, a single concept, or a single definition of homo religiosus's perception, does not capture or cover religion in all its manifestations. Hence we need a constant reconceptualisation of the perception of religion by both homo religiosus and the scholar.

\section{Reality}

I have already referred to Eliade's identification of religion (or the sacred) with reality. He claims that 'at the archaic levels of culture, the real - that is to say the powerful, the significant, the living - is equivalent to the sacred' $(1965,202$, emphasis in original). Elsewhere he states that 'the myth is regarded as a sacred story [...] because it always deals with realities' (1964, 6, emphasis in original). Realities, in turn, are something that is related to the origins of everything, and origins alone are something significant and valid, 
something that exists absolutely, and, unlike history, thus has a 'soteriological' meaning (1964, 34, 134, 140).

Thus, for Eliade, reality is the indisputable, impersonal foundation of a person's 'true' existence. It is something beyond the individual's capacity. Its validity is nevertheless proven by the circumstances under with humans live $(1964,51)$. Reality is the ground upon, and the model according to which, we should build our world and life. In The Two and the One Eliade states that religious experience (in this case, the Taoist experience of interior light) ultimately aims at reviving, in the deepest part of one's being, 'the harmony with the rhythms of the cosmos' $(1965,49)$.

If we essentialise the Eliadean understanding of reality ontologically, in the Aristotelian sense familiar to western thinkers, we are back to the Christianised concept of God as the 'unmoving mover'. This is what Eliade seems to be doing when he argues for example that 'a certain tribe live by fishing - because in mythical times a Supernatural Being taught their ancestors to catch and cook fish' $(1964,12)$ : the world is made by someone outside the world. But if, as I suggested in the previous section, we see reality as an interactive process, a constant recapturing of the fact that everyone is born into certain circumstances (see 1964,21), reality is not unchanging. What we call reality is a still image that captures the viewpoint of homo religiosus. It does not capture reality as such, but the ways in which it is lived true in human life (cf. Studstill 2000, 181-184). Briefly, Eliade's notion of reality is not Aristotelian. Rather, it corresponds to that of Hinduism and Buddhism, which see the 'true reality' without beginning or end, locate it 'beyond' or 'outside' time (Eliade 1964, 61-63) and claim to apprehend it 'in terms of immediate experience' only $(1965,82)$.

Such an experience Eliade calls authentic. Its opposite is unauthentic experience, which Eliade characterises, in The Two and the One, by stating that (in the 1950s) modern western man 'feels himself torn and separate' from reality. This separation in turn 'has taken the form of a fissure, both in himself and in the world', which 'implies a fatal disaster for the human race and at the same time an ontological change in the structure of the World' $(1965,122)$. To remedy the situation one has to become religious, since, Eliade argues, 'the more religious he [the modern man] is, the more he enters into the real' and the less he feels himself separate or broken (1971, 83-84). A separate person is in Eliade's parlance unauthentic, whereas a religious one, i.e., one who has 'entered' into, or perhaps 'contacted' with, real, is authentic. Briefly, Eliade claims that religion somehow changes or transforms a person, who thereby gains 'a new and superior way of being' (1965, 27; see also ibid., 72-73). What might this mean? 
My view is that Eliade is making some sort of Heideggerian assumption as to the 'nature' of being and reality. The two of them use similar terms. Eliade speaks of man's mode-of-being-in-the-world (or existential situation), and Heidegger of one's in-der-Welt-sein. Both argue that humans are what they are due to preceding deeds and events. According to Eliade, the 'essential precedes existence' $(1964,92)$, meaning that humans are what they are 'today because a series of events took place $a b$ origine' (ibid.). Hence reality amounts to a sort of world-building or world-making. In Eliade's words, '[i]n the final instance, the religious man comes to feel himself responsible for the renewal of the World' (1965, 159, emphasis in original).

In Myth and Reality Eliade states $(1964,19)$ that 'one "lives" the myth in the sense that one is seized by the sacred, exalting power of the events recollected or re-enacted'. Thus reality manifests itself through human activities. If this is the case, humans are able to change their ontology. However, Eliade seems to assume that only certain types of change are acceptable, those from the unauthentic to the authentic, from the 'everyday world' to that 'impregnated with the Supernatural's presence' $(1964,19)$. Although Eliade does not actually say so anywhere, this emphasis on 'right' and 'wrong' modes of being evokes ethics; not all one's relations to oneself, the others and to one's surroundings are equally good (cf. Eliade 1971, 153). In the final analysis, what Eliade calls reality is thus in my interpretation an ethical re-evaluation of the value and course of human life (cf. Wasserstorm 1999, 225-234). For Eliade, 'reality' is not a methodological concept but an epistemological statement. He speaks of reality not in order to clarify the nature of religion, but to emphasise a particular standpoint in the study of homo religiosus. If we do not postulate religion as a human 'mode-of-being' in its own right we will not try to understand religion, we will try to undermine it. And that is something Eliade does not accept, because he sees religion as the main, or crucial, factor in human world-making.

\section{The Human Mode-of-being}

What sort of mode-of-being, then, is religion? I have already mentioned that, according to Eliade, religion is a means whereby a human being establishes his or her relation to reality and finds himself or herself as an authentic being. Eliade states that religion 'express typical human situations' and 'form an integral part of the history of the spirit' $(1965,12)$. Thus Eliade refuses to explain religion in non-religious terms. Instead, he uses religion (or the sacred) as an explanation, and describes the myriad ways of recreating an 'authentic' mode-of-being in the world (see Eliade 1964, 41-50). In other 
words, where many scholars of religion argue that religion varies in time and space and thus cannot be explained or understood by ignoring cultural and social contexts, Eliade argues that the basic orientation of religious persons always has a 'changeless' or 'ontological' structure, which can be comprehended by 'intelligent sympathy' only and in terms familiar to homo religiosus $(1965,12)$.

But how can religion be understood, or even described, if we ignore historical, cultural and other factors? Does not such an attempt eradicate historical and cultural variety as well as the difference between religion and science, and between the studying subject and studied object, which are among the cornerstones of western science? And does it not lead the scholar to religious rather than scientific discussion, hence turning him or her from a scholar into a preacher? No, says Eliade. Our knowledge about 'archaic peoples', by which Eliade means religious peoples, shows that they always resorted to certain types of patterns in order to recreate the 'cosmos', the 'world', their mode-of-being (Eliade 1964, 42 et passim). Briefly, Eliade emphasises the use of comparative method in analysing homo religiosus's view of religion. But is this not a tautological answer?

Phenomenologically speaking, this dilemma is called the hermeneutic circle. Speaking religiously about 'eternal' or 'changeless' elements of religion means that the scholar is moving within the same context, trying to establish connections, a sort of dialogue, between his or her way of seeing religion and that of the homo religiosus under examinination. Speaking scientifically about religion implies a contextual change, the scholar's translation of one language (that of homo religiosus) in terms of another one (that of the scholar). The first option means that the scholar struggles to enter more deeply into the subject itself. The second means that he or she deepens his or her view on the subject by understanding that what he or she calls 'religion' is merely his or her construction of religion, not what homo religiosus believes religion to be. Eliade goes a little further; he assumes that, basically, homo religiosus and the scholar share an understanding of 'true reality', 'true' mode-of-being, and that the scholar's task is merely to 'remember' that reality (see Eliade 1964, 136-138).

This may seem a rather unscientific way of approaching religion. But the choice of understanding what religion is or how to describe it is crucial in terms of the scholar's dialogue with his or her subject of study. Speaking about religion in homo religiosus's terms implies that one sees religion not only as a mode-of-being-in-the-world, but as a mode that has something to say to him or her. Speaking non-religiously about religion implies that 
religion has no particular importance for the scholar as a human being. For Eliade, it seems, a non-religious understanding of religion also means that one denies the possibility of human access to 'true reality', or - what seems to amount to the same for Eliade - denies the irreversibility of time and history (see Eliade 1964, 140).

Why should we care about such matters? Does a study have to have some personal importance? I think that if we put ethics above ontology, as I have suggested Eliade can be read to have done, it matters a lot. A study has, or may have, several and conflicting implications. It is not merely a piece of scientific knowledge or data. It says something about someone or something to somebody. Through words a study so to speak creates or re-creates its 'object', or at least conceptualises it in the mind of the reader. This process also changes the reader's understanding of the 'object' reviewed. In Foucauldian words, by means of his or her study a scholar wields power. And since a study also implies the mode-of-being-in-the-world of the scholar, his or her authenticity or non-authenticity, as Eliade puts it, this 'mode' becomes part of the study. That is, a scholar and a study are 'authentic' or 'unauthentic' not only in the common sense of being genuine or false, but also in terms of their effects, which can be ethical or unethical. If we understand Eliade's statements about the mode-of-being-in-the-world in this sense, we also understand that his concepts 'authentic' and 'unauthentic' are not reified terms but have different meanings in different situations.

A critical observer might argue that I am pushing my rethinking of Eliade too far. Did not Eliade for example imply, if not explicate, that although different religions (or, more accurately, different persons) use different symbols to express and interpret religion, the symbols always refer to, and form, a coherent whole, which ultimately is the same yesterday, today, and for all time? Did not Eliade's talk about eternal return mean that for example Buddha, Jesus and Muhammad all spoke about the same reality, the same sacred, although by means of different symbols? And do not ethics disappear at the point where good and evil lose their meaning in their ultimate coincidentia oppositorum (see Wasserstorm 1999, 77-79)?

\section{Symbols}

My hypothesis is that Eliade would answer these questions by saying that Buddha, Jesus and Muhammad all represent an authentic mode-of-beingin-the-world. They 'existed' in an authentic way, created a 'real' world, because in Eliade's view they all communicated by means of symbols with and about the sacred (see Eliade 1964, 139-145; cf. Studstill 2000, 185-186). 
They even used similar symbols, although their emphasis on individual symbols and their interpretation of details differed. (See Eliade 1961b; 1976.) In my opinion, what Eliade wants to say was that the use of symbols is somehow natural to humans. He argues that there exists a limited number of important religious symbols, a sort of supreme hierophanies, which have widespread or even 'universal' meaning and which make up a system or set of patterns. The composition of this set may vary (that is, the symbols may be arranged in various ways to make up a 'whole'), but its ultimate or fundamental meaning, its 'essence', can always be expressed by the concept of the sacred. If symbols are understood in this way, the scholar's task is to determine how a particular 'whole' is composed and how it is used to create a reality and a mode-of-being-in-the-world; these are to be understood in terms of the sacred or ethical, not in terms of the profane or non-ethical.

As I have noted, Eliade's critics seem to suppose that this form of study of religions is a tautology; the scholar simply makes an inventory of symbols in different religions and concludes, or asserts, that they all speak about the same, the sacred. I think this is inaccurate. It is true that Eliade for example does not much speculate on or discuss the concept 'sacred' (see Eliade 1971). But I also think that he was not so simple-minded as to argue that all symbols are basically nothing more than different types of maya, veils which the scholar has to remove in order to perceive the truth. But how can a study of symbols 'reveal' the sacred?

Eliade would probably have said that the study of symbols is an art of integration: one does not try to find something 'behind' the symbols, but to understand how they are used to create or convey meanings, to connect things, ideas, actions, etc., to make up a 'whole' (see Eliade 1965, 200-201). In Eliade's opinion, this is achieved above all in oral cultures. It was no accident that he was particularly interested in 'archaic' and 'primitive' cultures and societies, which in his opinion emphasised more face-to-face contacts and oral communication than do 'modern' or 'post-modern' ones.

In oral cultures, as Eliade sees them, symbols are expressed by sacred narratives and actions, in other words myths and rituals. Both are used to reconstruct 'primordial acts', deeds of gods and heroes which have created the world and everything in it at the beginning of time (see Eliade 1964; 1971). Thus myths describe and rituals imitate creative acts and can be used for the recreation of the 'authentic mode'; this, for Eliade, means the restoration of what is real, one's return to the origins of one's being. In other words, oral cultures are inseparably connected with being, with existence and accordingly with identity. When something is retold in a myth 
or re-enacted in a ritual, a human mode-of-being-in-the-world and human identity (authenticity) are re-established (cf. Ricœur 1984). For Eliade, myths and rituals function as a means of identity-making; in my view, Eliade is unable to comprehend identity without the support of tradition or continuity, or continuity without reference to a frame which legitimates it, namely, the sacred. Tradition and the sacred are 'given' in much the same sense as Durkheim's social facts: one does not invent them, but is born within them. But to internalise them, to modify them according to the situation, one has to retell them. Different religions and different ways of patterning symbols are means of expressing our aspirations to narrate and act out ourselves as existing, or 'real', individuals and societies.

One not fully clarified question in Eliade's view on symbols is their relation to human culture. Are they human constructions or do they have some meaning or significance independent of humans? What I have said thus far suggests that religious symbols are created and transformed by homo religiosus to refer to and to represent the sacred. Eliade himself argues in The Two and the One, that ' $[\mathrm{w}]$ hen the mind is no longer capable of perceiving the metaphysical significance of a symbol, it is understood at levels which become increasingly coarse' $(1965,100)$. This can be read as suggesting that interpretations of symbols are made by humans, whereas symbols 'as such' are more than merely a human construction. But the question remains, what actually is this 'more'? Does it have an 'essence', in the classic theological or philosophical sense of the word? Or is it simply that a symbol is some sort of 'social fact', whose significance grows out of collective rather than individual 'construction'? Eliade's statement may be understood both ways, but I prefer the latter interpretation.

\section{Conclusions}

To conclude, I first attempt an answer to my question: What does Eliade mean when he states that he wants to understand religion at its own level? Second, I outline my view of going 'beyond' Eliade.

To begin with, Eliade defines religion in terms, among others, of the real, the sacred, being-in-the-world and symbols. He discusses or presents all these concepts autonomously and on their own terms, not in terms of non-religious entities. Thus he insists, in the manner of Heidegger, Schleiermacher and others, that an interpretation of a phenomenon does not affect the phenomenon; it remains what it is and must be interpreted as such.

This kind of study of religion essentialises its 'object' if we insist that we really can grasp the 'thing itself', as Schleiermacher for example seems 
to believe. This, in my opinion, we cannot do; there is always a distance between the scholar and the object, person, symbol, etc. which he or she is studying. Eliade tends to ignore this distance. He seems to presume that the scholar can take the place of homo religiosus, because the scholar too is a religious person. Indeed, he or she can take that place, but it is never identical with that of the homo religiosus whom one is studying; the 'object' of our study always remains somehow other. What we can do - and this is how I can imagine that we study a phenomenon at its 'own level', i.e., without reducing it from a religious context to some other one - is to accept the imperfection and partiality of any interpretation: the sacred remains sacred, because no interpretation exhausts it.

In order to respect reality, the sacred, and the mode-of-being-in-the world of homo religiosus, however, the scholar has to encounter all of these in the manner of what Martin Buber called I-Thou relations, and not as an object that one is to subjugate. In I-Thou relations the scholar sees the other as something else than him- or herself, and also as something open and accessible, not determined by preconceived categories. This is what Eliade aims at but never achieves, because contrary to his expressed intentions he tries to show that only the historian of religion, not homo religiosus, sees the whole truth about religion. By taking homo religiosus seriously as our partner in debate, by contextualising him or her historically (see Studstill 2000, 178-180), by accepting his or her view of religion (that is, his or her way of constituting religion as structures of mind and actions of body) as the starting-point - though not the end - of our interpretation of religion, we may be able to go, in a positive sense, beyond Eliade.

My reading of Eliade's methodology has connections with phenomenological philosophy of the type of Husserl and Heidegger. However, since Eliade's approach to the history of religions is inseparable from his belief - I think this is the correct way to put it - in the continuous renewal of human 'mode-of-being', he does not merely analyse his data; he also urges both scholars and others to realise in their consciousness the existence (or, better, making of) the world and to put this to creative use in their Lebenswelt (as Husserl might have put it). This is the part of Eliade's legacy which many scholars of religion have found hard to accept. According to them, the scholar is a scientific analyst who discovers something new, not a creative individual who recreates him- or herself by continuously returning to the origins of the sacred (cf. Eliade 1964, 146-157).

Nevertheless, if we study religion as a way and a part of human life, in my opinion we have to try to understand the argument that for homo re- 
ligiosus speaking of religion means communicating something that is 'real', in a sense a scholar can never fully explain (except within homo religiosus's own framework); and this 'something' has something to do with the being (or living) of a human being and the interpretation of one's experience of that being (or living). Religion is not fully understood by asserting that it is a reflection of culture, history, society or one's self. In other words, in my opinion we understand religion more fully if we accept that for homo religiosus it contains both changeable elements (which science can explain) and 'eternal' ones (which science can merely describe). By accepting this, we relate religion both to our own humanity and to that of other humans around us. To study religion is not merely to explain it. To study something also means to affect it, to change it - to establish for oneself the ideal of the best of human life, as Husserl (1998) would have put it.

However, the study of homo religiosus cannot be limited, as Eliade often does, to attempts to illuminate the experience, being or life of mystics or other 'transfigured' persons'. It has to include the 'ordinary', 'everyday', 'popular', 'official' and 'institutional' religions of 'common' people as well. I believe that Eliadean concepts, such as those discussed above, can be applied to these sorts of religions and these kinds of religious people as well. Eliade perhaps had similar purposes; he devoted much space to folk religiosity or as he sometimes termed it, 'cosmic Christianity' $(1964,170)$. I think that Eliade's major mistake here was to suppose that the structure of experiencing being or life is always roughly similar, that the structure of the sacred cannot truly change. I think otherwise. By allowing real differences between, say, Romanian peasant rituals and Vedic Brahmans, we may vindicate Eliade's argument $(1965,176)$ - never really tested by himself - that a religious man (or woman) makes himself (or herself), by showing how that making actually takes place in any given case. We can thus put to the test Eliade's claim that religious studies is a discipline devoted to the empirical analysis of symbols that appear in history and are in one way or another defined as religious $(1965,191)$.

Eliade calls this kind of self-imposed limitation of religious studies 'dodging' (1965, 193). In Eliade's opinion, the 'work' expected of a scholar, in the final analysis, is to create a general theory of religion by familiarising oneself with all sorts of religious materials. I am sure that we need a general notion of what we mean by the concept 'religion'. However, I am equally sure that a general theory does not explain religion except at a general level. A general theory allows us to understand - if we're lucky - why and how humans usually tend to be religious. But we need a more restricted notion 
of religion to understand why a given person or group at a given place and time is religious in a given way, and not in some other. In this respect too we need to go beyond Eliade.

I give an example. In The Two and the One, writing about the symbolism of the cosmic tree, Eliade notes that it has different significance in different cultures. He continues $(1965,198)$ : 'The historian of religions will have to elucidate the reasons why a certain culture has kept, developed or forgotten an aspect of the symbolism of the Cosmic Tree - and, in doing so, he will come to penetrate more deeply into the soul of that culture and learn to differentiate it from the rest.' We need not accept Eliade's presupposition that the 'ideal' cosmic tree already contains the symbolism it has in a particular culture. I think, on the contrary, that there is no pre-existing aspect to be singled out; the particular symbolism arises, or grows out, of local circumstances. To put it differently: unlike homo religiosus, the scholar does not see local symbols as hierophanies of the sacred; the sacred is the scholar's interpretation attached to local symbols, which thus are transformed into a religion.

Nevertheless, the sacred in general and its local or particular interpretations are connected, as Eliade insisted; the latter cannot exist without the former. A scholar creates his or her view on religion (in general) what he or she assumes to be religious for a particular person or people. The homo religiosus regards his or her view as the religion and may reproach the scholar for distorting 'universal' truths with (from his or her viewpoint) partial interpretations. Eliade's approach does not provide us with a clear clue as to how to at the same time preserve a difference between a scholar's and a homo religiosus's view and yet create a bridge between them, because he sticks to generalities 'revealed' by his comparative method and ignores particularities of local societies. Nor does his view explain how, why and under which particular circumstances movement or 'alienation' in fact occurs from the authentic to the unauthentic mode-of-being. My guess is that Eliade here leaves aside human will, its freedom to choose, and human emotions, which in my opinion are necessary to make a mode-of-being either authentic or unauthentic.

Another shortcoming in Eliade's approach, in my opinion, is what Durkheim, in The Elementary Forms of Religious Life, terms 'effervescence' or 'sentiment', which I would describe as the social-emotional context in which cognitive models for religious beliefs and behaviour are created. Eliade concentrates heavily on cognitive, or at least structural, 'models' formulated in the past for individuals by 'supernatural' beings. Therefore, despite his 
repeated calls for creativity and imagination, Eliade leaves rather little space for the innovative creation of new models, for deviations from a supposed 'unifying' religiosity that explains why and how a particular aspect of the symbolism of, say, the cosmic tree becomes prevalent in a particular culture. Durkheim, to the contrary, emphasises the 'effervescent' coming-together of people as a group, giving rise to 'religious sentiments' and finally to new religious symbols. I suspect that Eliade's outlining of 'cosmic Christianity' can be interpreted in a similar vein, as cognitive, emotional and social interpretations of local cultures as to how one can recreate a 'real' not bound by time or space, the sacred, within the limitations of the concrete world.

What neither Durkheim nor Eliade discuss is the nature of the sacred. Is it always good, as both of them seem to believe? Or can something be sacred and yet evil? (See Kahn 2007.) If, as I have done, we postulate a homo religiosus as a subject with will, emotions and ethics, and if we see the sacred not as something 'given' but as a means whereby human beings order their world in such a way as to be able to communicate with what they regard as 'real', we have to accept that as a human construction the sacred can be evil as well. This, in my opinion, is a great challenge to our understanding and definition of religion and of homo religiosus. Answering that challenge by revisiting the ways in which humans use symbols, which they connect with the 'real', to construct a 'mode-of-being' - or, as William Paden (1999) puts it, a 'world' - is one way of going 'beyond' Eliade.

\section{Bibliography}

\section{Dudley, Guilford III}

1977 Religion on Trial: Mircea Eliade and His Critics. Philadelphia: Temple University Press.

\section{Eliade, Mircea}

1961a Mythen, Träume und Mysterien. Übertrag. von Michael Bemedict \& Matthias Vereno. Salzburg: Otto Müller.

1961b Images and Symbols: Studies in Religious Symbolism. Tr. by Philip Mairet. Kansas City: Sheed.

1962 The Forge and the Crucible. Tr. by Stephan Corrin. London: Rider \& Company.

1964 Myth and Reality. London: Allen \& Unwin.

1965 The Two and the One. Tr. by J. M. Cohen. London: Harvill Press.

1971 Le sacré et le profane. Paris: Gallimard.

1976 Patterns in Comparative Religion. London: Sheerd \& Ward.

1977 No Souvenirs: Journal, 1957-1969. Tr. by Fred Johnson. New York: Harper \& Row. 


\section{Husserl, Edmund}

1998 [1924] Erneuerung als individualethisches Problem. - Aufsätze und Vorträge (1922-1937), 20-43. Husserliana XXVII, hg. von Thomas Nenon \& Hans Reiner Sepp. Dor: Kluwer.

Kahn, Paul W.

2007 Out of Eden: Adam and Eve and the Problem of Evil. Princeton: Princeton University Press.

\section{Laitila, Teuvo}

2000 Imagining Meanings: An Eliadean Look at Religion. - Temenos 35-36, 67-82.

\section{Marino, Adrian}

1981 L'hermeneutique du Mircea Eliade. Paris: Gallimard.

McCutcheon, Russell T.

2001 Methods, Theories, and the Terrors of History: Closing the Eliadean Era with Some Dignity. - Bryan S. Rennie (ed.), Changinc Religious Worlds: The Meaning and End of Mircea Eliade, 11-23. New York: State University of New York Press.

\section{Paden, William E.}

1999 Sacrality and Worldmaking: New Categorial Perspectives. - Tore Ahlbäck (ed.), Approaching Religion. Part I, 165-180. Abo: The Donner Institute.

\section{Rennie, Bryan S.}

1996 Reconstructing Eliade: Making Sense of Religion. New York: State University of New York Press.

\section{Ricoœur, Paul}

1984 Time and Narrative, vol. 1. Tr. by Kathleen McLaughlin \& David Pellaeur. Chicgao: The University of Chicago Press.

\section{Saliba, John A.}

1976 'Homo religiosus' in Mircea Eliade: An Anthropological Evaluation. Supplementa ad Numen, altera series V. Leiden: Brill.

\section{Smart, Ninian}

1978 Beyond Eliade: The Future of Theory in Religion. - Numen 25 (2), 171-183.

\section{Studstill, Randall}

2000 Eliade, Phenomenology, and the Sacred. - Religious Studies 36 (2), 177-194.

Wasserstorm, Steven M.

1999 Religion after Religion: Gershom Scholem, Mircea Eliade, and Henry Corbin at Eranos. Princeton: Princeton University Press. 